\title{
Development of Unconventional T Cells Controlled by MicroRNA
}

\author{
Samantha J. Winter and Andreas Krueger* \\ Institute for Molecular Medicine, Goethe-University Frankfurt, Frankfurt am Main, Germany
}

Post-transcriptional gene regulation through microRNA (miRNA) has emerged as a major control mechanism of multiple biological processes, including development and function of $T$ cells. $T$ cells are vital components of the immune system, with conventional $T$ cells playing a central role in adaptive immunity and unconventional $T$ cells having additional functions reminiscent of both innate and adaptive immunity, such as involvement in stress responses and tissue homeostasis. Unconventional $T$ cells encompass cells expressing semi-invariant $T$ cell receptors (TCRs), such as invariant Natural Killer $T$ (iNKT) and Mucosal-Associated Invariant T (MAIT) cells. Additionally, some $T$ cells with diverse TCR repertoires, including $\gamma \delta T$ cells, intraepithelial lymphocytes (IEL) and regulatory $\mathrm{T}$ (Treg) cells, share some functional and/or developmental features with their semi-invariant unconventional counterparts. Unconventional T cells are particularly sensitive to disruption of miRNA function, both globally and on the individual miRNA level.

Edited by:

Francisco Sanchez-Madrid, Autonomous University of Madrid, Spain

Reviewed by: Pilar Martín Spanish National Centre for Cardiovascular Research, Spain

Cosima T. Baldari,

University of Siena, Italy

*Correspondence:

Andreas Krueger andreas.krueger@kgu.de

Specialty section:

This article was submitted to $T$ Cell Biology,

a section of the journal

Frontiers in Immunology

Received: 02 August 2019 Accepted: 10 October 2019

Published: 23 October 2019

Citation:

Winter SJ and Krueger A (2019) Development of Unconventional $T$ Cells Controlled by MicroRNA.

Front. Immunol. 10:2520. doi: 10.3389/fimmu.2019.02520 Here, we review the role of miRNA in the development and function of unconventional $T$ cells from an iNKT-centric point of view. The function of single miRNAs can provide important insights into shared and individual pathways for the formation of different unconventional T cell subsets.

Keywords: thymus, T cell, MAIT cell, NKT cell, Treg cell, $\gamma \delta \mathrm{T}$ cell, microRNA, miR-181

\section{UNCONVENTIONAL T CELLS}

$\mathrm{T}$ cells make up a central part of the adaptive immune system. Certain $\mathrm{T}$ cell populations, frequently referred to as unconventional $\mathrm{T}$ cells, share functional profiles of both innate and adaptive immunity. These innate-like $\mathrm{T}$ cells have the capacity to rapidly respond to non-cognate stimulation by releasing large amounts of cytokines on top of their characteristic T-cell receptor-mediated functions. In addition to direct anti-pathogenic actions, innate-like cells have also been implicated in stress responses and tissue homeostasis. Invariant Natural Killer T cells (iNKTs), certain $\gamma \delta \mathrm{T}$ cell populations, Mucosal-Associated Invariant T (MAIT) cells and Intraepithelial Lymphocytes (IELs) constitute key variants of unconventional $\mathrm{T}$ cells $(1-4)$. Thymus-derived regulatory $\mathrm{T}$ ( $\mathrm{t}$ Treg) cells share at least some developmental features with unconventional innate-like $\mathrm{T}$ cells and are therefore discussed here as well $(5,6)$.

Broadly, unconventional $\mathrm{T}$ cells are generated through two major developmental pathways. The vast majority of $\gamma \delta \mathrm{T}$ cells and a smaller percentage of IELs and iNKT cells are derived from $\mathrm{CD}^{-} \mathrm{CD}^{-}$co-receptor double negative $(\mathrm{DN})$ thymocytes $(7,8)$. In contrast, most IELs, iNKT cells, MAIT cells, and tTreg cells are formed after passing through the more mature $\mathrm{CD} 4^{+} \mathrm{CD} 8^{+}$ double-positive (DP) thymocyte stage in a process termed agonist selection $(7,9)$. In this review, we focus on the latter subset of cells. 
iNKT cells are characterized by their semi-invariant $\mathrm{T}$ cell receptor (TCR), which is comprised of an invariant V $\alpha 14 \mathrm{~J} \alpha 18$ $\mathrm{TCR} \alpha$ chain in mouse (V $\alpha 24 \mathrm{~J} \alpha 18$ in human) and TCR $\beta$ chains with a bias for $\mathrm{V} \beta 8, \mathrm{~V} \beta 7$, and $\mathrm{V} \beta 2(10,11)$. These TCRs recognize glycolipid antigen in the context of the non-classical MHC molecule CD1d (12). In the thymus, iNKT-cell development can be divided into four consecutive stages ( $\mathrm{S} 0-3)$ based on differential expression of CD24, CD44, and NK1.1 $(13,14)$. Of note, S2 cells $\left(\mathrm{CD} 44^{+} \mathrm{NK} 1.1^{-}\right)$have the capacity to leave the thymus and enter peripheral tissues, whilst S3 cells $\left(\mathrm{NK} 1.1^{+}\right)$ are mostly thymus-resident (15). Functionally, iNKT cells can be subdivided into NKT1, NKT2, and NKT17 subsets based on prototypical cytokine and transcription factor signatures (IFN $\gamma$ and T-bet for NKT1, IL-4 and IL-13 for NKT2 and IL-17 and ROR $\gamma$ t for NKT17) (16).

In mice, MAIT cells are considerably less abundant than iNKT cells (with the opposite being the case in humans). The semiinvariant TCR of MAIT cells consists of a V $\alpha 19 \mathrm{~J} \alpha 33$ TCR $\alpha$ chain in mice (V $\alpha 7.2 \mathrm{~J} \alpha 33$ in humans) and a biased TCR $\beta$ chain usage $(17,18)$. MAIT cell TCRs recognize vitamin B derivatives in the context of the MHC-class I related molecule 1 (MR1) (19). Similar to iNKT cells, intrathymic development of MAIT cells can be divided into intermediates based on expression of the surface markers CD24 and CD44 (20). There is evidence that stage 2 (S2) MAIT cells exit the thymus, whereas S3 cells represent recirculating or resident cells. Further similarities to iNKT cells exist, with the description of MAIT1 and MAIT17 cells, which preferentially reside within defined tissues and possess more similar transcriptome profiles to NKT1 and NKT17 cells, respectively, than they do to MAIT cells of different tissues (21). Whereas, ratios of MAIT17 and MAIT1 cells are skewed in favor of MAIT17 cells in virtually every organ, the opposite is the case for NKT17 and NKT1 cells. However, both MAIT17 and NKT17 cells are preferentially enriched in lung, skin, and the colonic lamina propria. Notably, no MAIT2 cells have been described, although production of IL-13 has been demonstrated in long-term stimulated human MAIT cells (22). Development of all iNKT and MAIT cell lineages depends on expression of the transcription factor PLZF encoded by Zbtb16 (20, 23, 24). Both iNKT cells and MAIT cells are selected on DP thymocytes rather than epithelial cells. These cells also provide essential signals to iNKT cells through homotypic SLAM family receptor interactions, albeit it remains to be established whether MAIT cells are equally dependent on such signals $(25,26)$. Recently, a minor subset of MAIT cells has been described that is selected on thymic epithelial cells rather than thymocytes, retains a naive phenotype and is independent of SLAM signaling (27). Despite it being wellestablished that iNKT cells are derived from cells that have received strong TCR signals, requirement of such signals remains a major open question in MAIT-cell development. Lack of efficient MAIT-cell development in germ-free mice has suggested that MAIT cells are selected on foreign antigen $(20,28)$. In fact, it has been demonstrated that DP thymocytes are capable of rapidly presenting exogenously administered antigen, resulting in recovery of MAIT cells (28).
IELs constitute one of the most numerous lymphocyte populations in the body. They support intestinal tissue homeostasis and the integrity of the epithelial barrier between gut lumen and the body. IELs comprise conventional $\alpha \beta T$ cells, $\gamma \delta \mathrm{T}$ cells as well as unconventional $\alpha \beta \mathrm{T}$ cells (29). The latter are characterized by lack of the co-receptors CD4 and $\mathrm{CD} 8 \alpha \beta$ and expression of the CD8 $\alpha \alpha$ homodimer. CD $8 \alpha \alpha$ IELs rely on strong TCR signals during development and are partially autoreactive $(30,31)$. Recently, two distinct IEL precursor populations have been identified (31). However, their interrelatedness and developmental fate remain elusive.

tTreg cells have a diverse TCR repertoire, which partially displays characteristics of autoreactivity (32). Consistently, intrathymic development of most tTreg cells requires strong signals through their TCRs (5). As a consequence, additional signals via CD28 and IL-2 are required to prevent emerging tTreg cells from clonal deletion. Development of tTreg cells can be characterized by successive expression of the signature transcription factor Foxp3 and the IL-2 receptor alpha chain, CD25. Some tTreg cells emerge from precursors expressing first Foxp3 and then CD25 and some tTreg cells are generated through a CD $25^{+}$Foxp $3^{-}$intermediate (33-36). Recently, it has been suggested that tTreg cells have distinct functions depending on their developmental origin (37).

Although basic principles of T-cell development are shared between mice and humans, there are some fundamental differences in regards to unconventional T cells. For instance, the $\alpha \beta$ vs. $\gamma \delta$ lineage decision in humans has distinct requirements for $\mathrm{NOTCH}$ signals when compared to the murine system $(38,39)$. Moreover, it has recently been suggested that the timing of agonist selection in humans might differ from that in mice (40). Another notable difference between mice and humans is the relative abundance of iNKT and MAIT cells. In mice iNKT cells are the predominant population, whereas in humans MAIT cells are much more abundant. The underlying reasons for this difference remain unknown. In this review, we focus on the murine system because genetic models have so far played a substantial role in uncovering cell-type specific microRNA (miRNA) function. Individual miRNAs discussed here are conserved between the two species. However, miRNA binding sites might show a lower degree of conservation. Therefore, it might be interesting to explore whether species-specific differences of miRNA-mediated gene regulation contribute to differences between human and murine unconventional T cells.

Despite some significant differences, it is evident that unconventional $\mathrm{T}$ cells share multiple developmental principles, such as the requirement for strong TCR signals and a second signal conferring protection from cell death (such as CD28 and IL-2 for Treg cells and SLAM family receptor signaling for iNKT cells). Of note, both commonalities remain hypothetical in the case of MAIT cells (41). Here, we review the role of miRNAs in development of unconventional T cells. Emerging roles for miRNAs may highlight further common features and differences between different types of unconventional T cells. 


\section{ROLE OF MIRNAS IN THE DEVELOPMENT OF UNCONVENTIONAL T CELLS}

miRNAs are a form of small non-coding RNA, which principally act as post-transcriptional regulators of gene expression. Upon maturation from precursors, individual miRNAs are incorporated into RNA-induced silencing complexes (RISC), binding to and destabilizing mRNA transcripts, blocking translation and promoting mRNA decay (42). The ability to simultaneously modulate hundreds of mRNA transcripts at a relatively low metabolic cost to a cell is a major advantage of miRNA-mediated gene regulation (43). Conditional deletion of critical components of the miRNA processing machinery, such as Drosha, Dgcr8, and Dicer, which results in loss of the vast majority of miRNAs, has revealed a particular sensitivity in the development of unconventional $\alpha \beta T$ cells to general miRNA deficiency. In contrast, intrathymic $\gamma \delta \mathrm{T}$-cell numbers remained comparatively unaffected by loss of all miRNAs, thus ultimately resulting in elevated overall frequencies due to preferential loss of $\alpha \beta$ lineage thymocytes (44).

Developing iNKT cells display a dynamic miRNA expression profile substantially different from conventional T cells. Deletion of Dicer or Drosha in lymphocytes or $\mathrm{T}$ cells results in near complete absence of iNKT cells $(20,45,46)$. miRNAdeficiency caused cell-intrinsic early stage blocks in development (Figure 1). Residual iNKT cells displayed reduced cytokine production and upregulation of CD69 following stimulation with the prototypical antigen $\alpha-\mathrm{GalCer}$, which argued that miRNA deficiency leads to a defect in iNKT TCR signaling $(45,46)$. An unbiased approach to identify miRNAs responsible for the developmental defect in Dicer-deficient iNKT cells was used, by comparing transcriptional signatures from Dicerdeficient iNKT cells to S1-2 and S3 WT iNKT cells. Matching differentially regulated Dicer-dependent genes with in silico predicted miRNA targets suggested several miRNAs to play a role in iNKT-cell development, such as miR-181 and members of the miR-17 92 cluster (47).

Similar to iNKT cells, development of MAIT cells is severely perturbed in the absence of miRNAs (20). In thymi of Tcell specific Drosha-deficient mice, MAIT-cell development was mostly arrested at S1 (20) (Figure 2).

Deletion of Dicer or Drosha results in defective Treg-cell development and function. T-cell specific deletion of miRNAs results in substantially reduced Treg-cell numbers in the thymus (48). In addition, residual miRNA-deficient Treg cells showed a reduced suppressive capacity and diminished homeostatic potential (48-50). Treg-cell specific ablation of miRNAs phenocopies loss of Foxp3, resulting in fatal multi-organ autoimmunity (50).

Taken together, developmental and functional defects in unconventional $\mathrm{T}$ cells in pan-miRNA deficient models highlight the critical role of miRNA-mediated post-transcriptional control in these cell types. However, the function of individual miRNAs and the corresponding underlying molecular mechanisms are only beginning to emerge.
Few miRNAs have shown to be critically involved in early conventional T-cell development, while agonist-selected $\mathrm{T}$ cell lineages have been demonstrated to be quite sensitive to miRNAmediated regulation. Some of the more notable miRNAs that have been found to modulate developmental processes in unconventional $\mathrm{T}$ cell populations are detailed below from an iNKT-cell centric perspective (Figures 1, 2).

\section{Let-7}

The let-7 family of miRNAs is the most abundant family of miRNAs in the genome and they play an important role in iNKT-cell development. Fetal hematopoietic cells express the LIN28A and LIN28B proteins which bind to let-7 precursor molecules, promoting their degradation, and preventing the biogenesis of functional let-7 miRNAs. This repression of functional let-7 miRNA expression shapes fetal lymphopoiesis (51). Exploiting this knowledge, transgenic expression of LIN28 has been employed to cause let-7 loss-of-function (52). Vice versa, inducible ectopic expression of mutated let-7 lacking binding sites for LIN28 results in let-7 gain-of-function (52). Analysis of these models provided evidence that dynamic upregulation of endogenous let-7 expression throughout thymic iNKT-cell differentiation results in a downregulation of PLZF, through direct targeting of Zbtb16 mRNA (Figure 1). Let-7-dependent reduction in PLZF expression limits development of iNKT cells, whereas loss of function of let-7 rescued iNKT-cell development in Zbtb16-haploinsufficient mice. In addition, let-7 directs iNKT cells to terminally differentiate into IFN $\gamma$-producing NKT1 cells. In contrast, inhibiting the upregulation of let-7 miRNAs allowed iNKT cells to maintain high PLZF levels and favored the development of IL-4-producing NKT2 and IL-17-producing NKT17 cells. Dynamic upregulation of let-7 miRNAs during iNKT-cell development was triggered by exogenous stimuli in the thymic medulla, including IL-15, vitamin D, and retinoic acid (52). Given the requirement for PLZF in MAIT-cell development, it can be hypothesized that let-7 miRNAs may play a role in the generation of this cell lineage as well. Moreover, analysis of MAIT-cell development upon dysregulation of let-7 function may shed light on the relevance of differences in PLZF expression dynamics during iNKT- and MAIT-cell development.

\section{miR-17 92 and Its Paralogs miR-106b 25, and $\mathrm{miR}-106 \mathrm{a} \sim 363$}

Comparisons between WT and Dicer-deficient developing iNKT cells revealed an increase in the expression of TGF $\beta$ receptor II (TGFBRII) mRNA in the absence of miRNA (47). TGFBRII is a subunit of the heterodimeric receptor for TGF $\beta$, a cytokine known to protect against clonal deletion and promote the development of iNKT cells and other agonist-selected lineages (53-56). During S1 of iNKT-cell differentiation, TGF $\beta$ signaling through TGF $\beta$ RII sustains iNKTcell expansion. Upon progression through development S2 iNKT cells downregulate TGF $\beta$ RII, which is a requirement for normal progression to S3. In Dicer-deficient mice, lack of regulation by miRNAs led to unconstrained TGF $\beta$ RII expression and therefore TGF $\beta$ signaling, as well as an 
accumulation of early stage iNKT cells (47). The miR17 92 cluster was experimentally validated to have two target sites in the Tgfbr2 $3^{\prime}$ UTR, which coincided with an inverse relationship between the expression of miR-17 92 miRNAs and TGF $\beta$ RII. miR-17 92 comprises 6 miRNAs of 4 families. In addition, the cluster has two paralogs, miR-106a-363 and miR-106b 25, with different expression profiles. miR-17 92 is the predominant paralog in hematopoietic cells and its loss results in impaired B-cell and T-cell development (57, 58). Compound loss of additional paralogs results in more severe defects and individual targeting of members of the
miR-17 92 cluster has provided a better understanding of miR-17 92 function (59).

Analysis of mice deficient in miR-17 92 and its paralogs revealed an increase in TGF $\beta$ RII expression and therefore TGF $\beta$ signaling, while simultaneously demonstrating early iNKT cell defects at S2 (Figure 1). Interestingly, double-deficiency of Dicer and TGF $\beta$ RII did not rescue frequencies or numbers of iNKT cells but appeared to aid cells stuck at S2 to differentiate into S3. Frequencies of S1 iNKT cells remained the same in Dicer and Dicer-TGF $\beta$ RII double-deficient mice, revealing that potential regulation of TGF $\beta$ RII expression by miR-17 92 cluster miRNAs

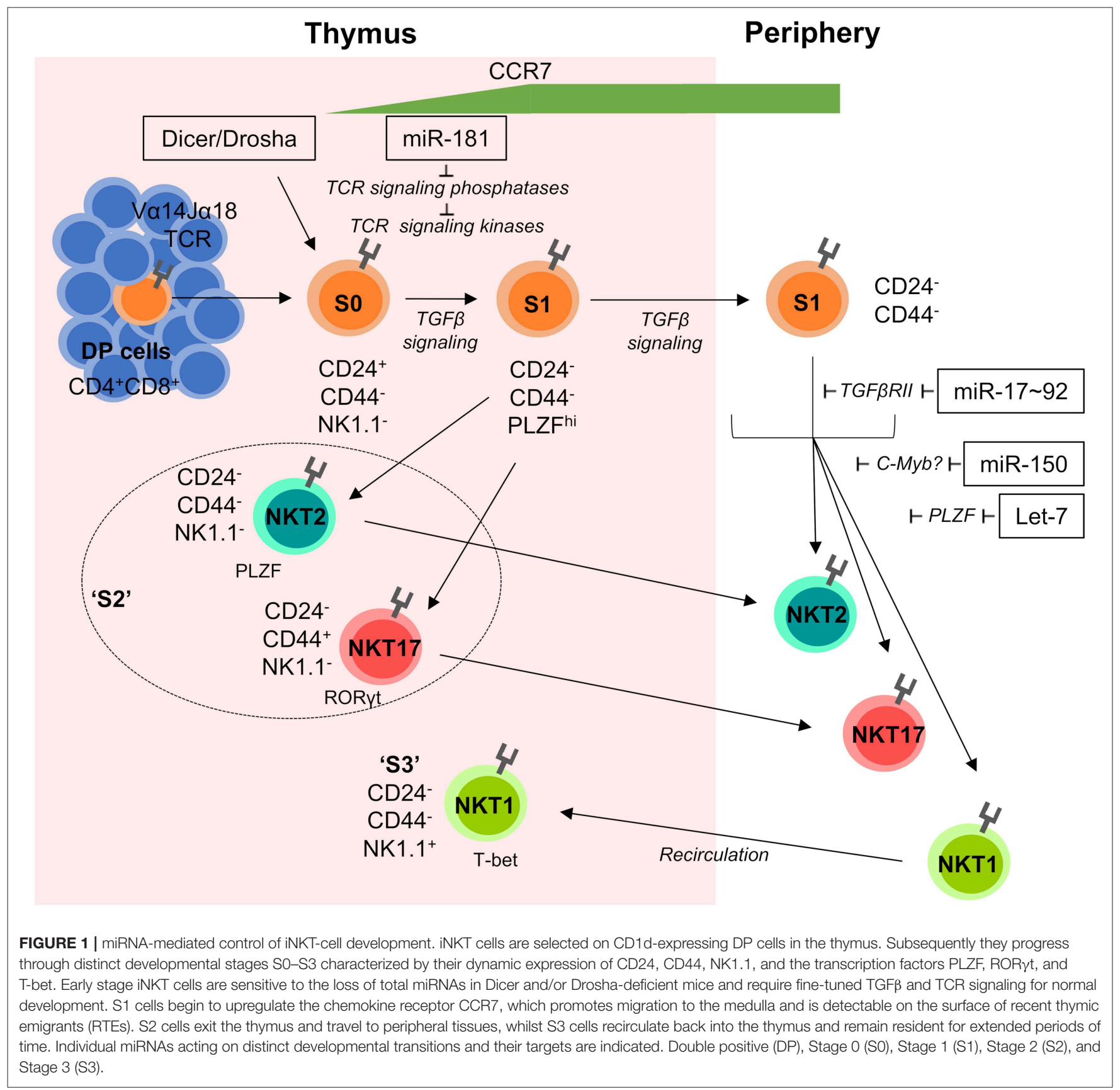




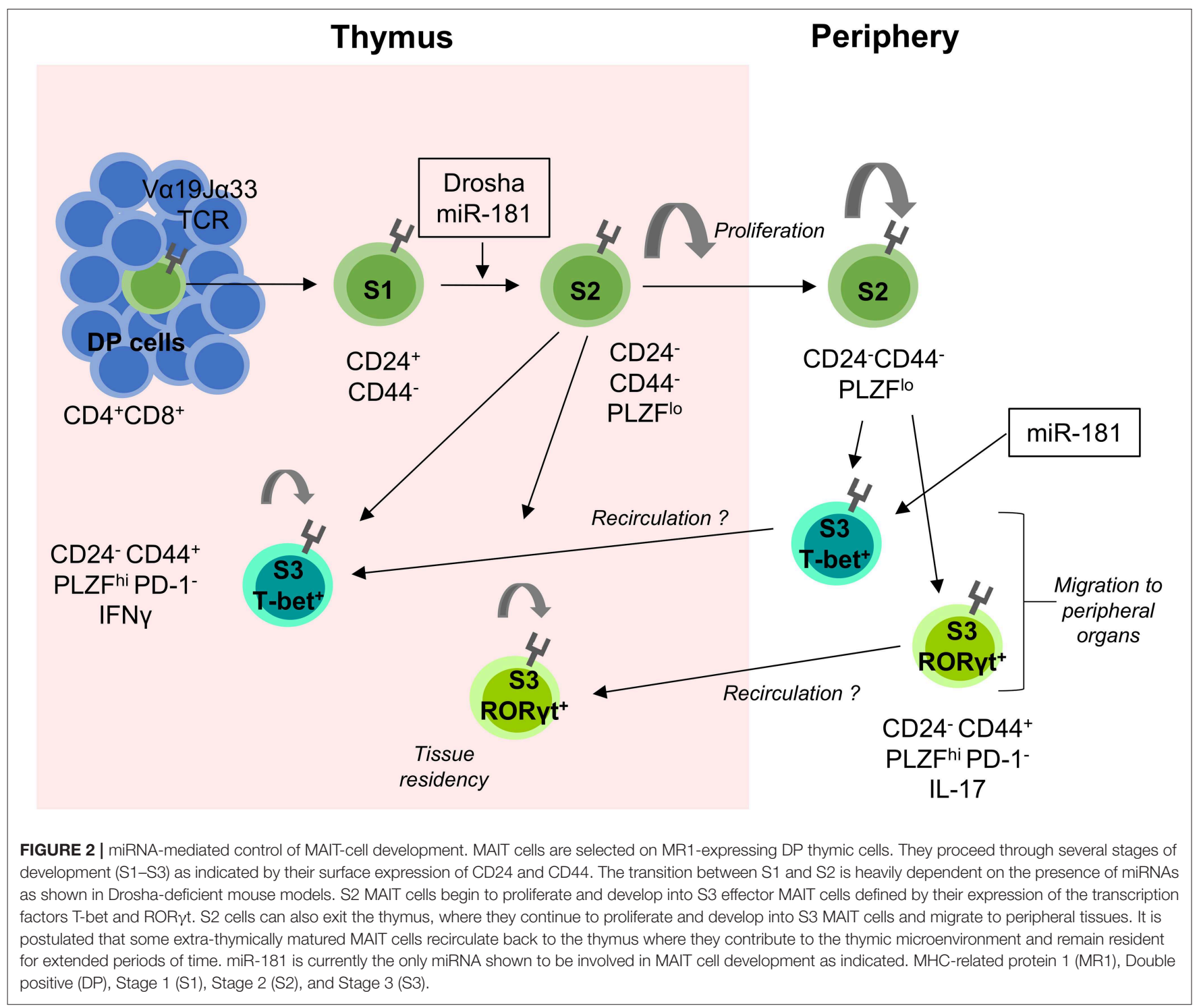

promotes progression from S2 to S3 (47). Notably, both Dicer deficiency and miR-17 92 family deficiency resulted in a virtual absence of NKT17 cells (47). Whether miR-17 92 and/or TGF $\beta$ signaling contribute to MAIT-cell development remains elusive. In contrast, TGF $\beta$ signaling is pivotal for induction of Treg cells from naive precursors $(56,60)$ and may also contribute to Tregcell development in the thymus (61-64). However, there is no direct evidence for a mechanistic link between miR-17 92 and TGF $\beta$ signaling in either of these processes. Rather, the role of miR-17 92 in Treg cells appears to be more complex. miR17 92 has been implicated in regulation of IL-10 production by Treg cells with loss of miR-17 92 resulting in reduced suppressive capacity (65). By contrast, loss of miR-17 alone resulted in enhanced suppressive capacity, presumably due to de-repression of critical co-factors of Foxp3 (66). Thus, the role of miR-17 92 family miRNAs in Treg-cell development and function remains to be fully understood. It is particularly noteworthy that mice with deletion of miR-17 92 in all $\mathrm{T}$ cells are more resistant, whereas mice with Treg cell specific deletion of miR-17 92 are more susceptible to experimental autoimmune encephalitis when compared to WT mice $(65,66)$. These findings indicate diverging roles of this miRNA cluster prior to and after Foxp3 expression in Treg cells, suggesting major differences in induced and thymus-derived Treg cells with regard to miR$17 \sim 92$ function.

\section{miR-150}

miR-150 is dynamically expressed during development of iNKT cells with lowest expression at S1 followed by progressively increased expression through to S3. miR-150-deficiency resulted in an overall decrease in thymic iNKT cells, appearing to have a mild defect in the transition from S2 to S3, despite normal levels of S1 iNKT cells $(67,68)$ (Figure 1). Ubiquitous ectopic expression of miR-150 also resulted in an overall reduction 
in iNKT cells, displaying a developmental block between S1 and S2, through increased numbers of S1 iNKT cells (67). Perhaps an explanation for the similar phenotypes between miR-150-deficiency or transgenic ectopic expression lies in the need for specific constraints in miR-150 expression at precise stages of iNKT-cell development. For example, it could be the case that early iNKT cells require low levels of miR-150, explaining the normal progression of iNKT cells to S2 in miR150-deficient mice followed by a block in further development due to a potential requirement for elevated levels of miR-150. Conversely, transgenic overexpression of miR-150 is likely to result in constitutively upregulated miR-150 at each iNKT-cell developmental stage, which may downregulate genes or pathways that are needed to move through development normally. If low expression of miR-150 was a requirement during early iNKT-cell development, then this would explain the block seen in miR150-transgenic mice. Alternatively, huge proliferative expansion of iNKT cells in the early stages of development (69) could also explain the larger reduction in iNKT-cell numbers in miR-150transgenic mice. Furthermore, increased production of IFN $\gamma$ by splenic iNKT cells in miR-150-deficient mice (68), may be a result of skewed iNKT differentiation toward the iNKT1 subset. C-myb was identified as a potential target of miR-150 $(67,68$, 70), with heterozygous c-myb-deficiency showing a reduction in splenic iNKT cells in mixed bone marrow chimeras, similar to transgenic expression of miR-150 (67). Further evidence is required to confirm the relationship between c-myb and miR150 in the regulation in iNKT cells. This combined deficiency and overexpression data suggests that a dynamic and tightly regulated expression of miR-150 is required for normal iNKTcell development. Recently, miR-150 has also been implicated in the peripheral differentiation and homeostasis of IELs (71). Mechanistically, it was suggested that miR-150, via inhibition of c-myb, limited expression of miR-20. In turn, reduced expression of miR-20 allowed for sufficient levels of TGF $\beta$ receptors to be expressed. Thus, miR-150-deficient IELs had reduced levels of TGF $\beta$ receptor. Notably, numbers of $\gamma \delta$ IELs were most drastically reduced in the absence of miR-150. Despite the role of miR-150 in peripheral IELs, their intrathymic development was independent of miR-150. As the intrathymic generation of IELs is also controlled by TGF $\beta$, this finding suggests that regulation of TGF $\beta$ signaling by miR-150 is context-dependent.

\section{miR-155}

miR-155 was shown to have a mild effect on iNKT-cell development. Germline deletion of miR-155 shows relatively normal development and function of iNKT cells (72). However, transgenic overexpression of miR-155 resulted in a substantial block in development at S2, coupled with a reduction of the peripheral iNKT cell compartment (73). miR-155 expression was identified to progressively decline throughout iNKT-cell development, ending with the lowest expression in S3 cells (73). This suggests that tightly controlled miR-155 expression is required for normal iNKT-cell development. The Ets 1 and ITK transcripts, modulators of TCR signaling and maturation, respectively, were brought forth as potentially relevant targets of miR-155 via in vitro luciferase assays. Mouse models deficient in Ets1 and ITK show a correlation in iNKT-cell developmental phenotypes to miR-155 transgenic mice (74-76). Interestingly, miR-155 transgenic mice showed upregulation of both targets in S1 and S2 cells, followed by a downregulation in S3, suggesting that increased expression of miR-155 in the earlier stages of iNKT-cell development does not render Ets1 and ITK susceptible to miR-155-mediated control (73).

In addition, miR-155 is the major miRNA shown to play a role in Treg-cell development. Foxp3 binds to the promoter and directly regulates the expression of miR-155's host gene Bic, which does not encode a functional protein (77). Impaired fitness coupled with inferior Foxp3 expression and stability was observed upon deletion of miR-155 (78). miR-155-deficient mice show reduced Treg-cell numbers (79) and upregulated suppressor of cytokine signaling 1 (SOCS1) (78). SOCS1 is a negative regulator of STAT5, a key downstream effector of IL$2 \mathrm{R}$ signaling, which is consequently diminished in miR-155deficient mice $(78,80)$. It has been suggested that during Tregcell development, induction of Foxp3 drives high expression of miR-155, maintaining the competitive fitness of Tregs (78). The miR-155/SOCS1 axis in Treg cells is one of only a few examples of rigorous analysis into the contribution of a single mRNA target to the overall function of miRNA-mediated regulation. To this end, a mutation in the Socs 1 3' UTR was introduced to disrupt the interaction between Socs 1 mRNA and miR-155 and thus relieving SOCS1 from miR-155-mediated control (81). This analysis showed that some effects exerted by miR-155 were directly attributable to SOCS1, such as Treg-cell homeostasis, but others such as regulation of antiviral immunity, were not. Overall, regulatory functions exerted by miR-155 highlight the context-dependency of miRNA action.

\section{miR-181}

Six members of the miR-181 family have been identified in mice and humans. The family is divided into three mini-clusters, miR$181 \mathrm{a} / \mathrm{b}-1, \mathrm{a} / \mathrm{b}-2$, and $\mathrm{c} / \mathrm{d}$, each of which is encoded on a separate chromosome. Mature miR-181a-1 and a-2 as well as b- 1 and b2 share an identical sequence. Mature miR-181a-1 and b-1 are encoded by murine chromosome 1 and are situated $\sim 150$ bp apart. High expression of the miR-181a/b-1 cluster is observed in the thymus, accounting for $\sim 98 \%$ of all the miR-181 species (82).

miR-181a/b-1 is dynamically expressed throughout thymocyte development and accounts for the largest enrichment of a miRNA family at any stage of development (83). This enrichment occurs at the DP stage, during which thymocytes undergo selection $(83,84)$. Transcripts containing predicted seed matches to miR-181 family members are depleted at the DP stage and are contrastingly enriched at the DN3 stage of development (83). So far, miR-181a/b-1 has been implicated in TCR signaling and thymocyte selection during these developmental stages $(82,85-87)$.

TCR signaling requires a host of coordinated phosphorylation and dephosphorylation events within a network of intracellular signaling molecules. $\mathrm{T}$ cells express over 40 different negative regulators of TCR signaling including multiple phosphatases for each of the fundamental TCR signaling kinases, such as Lck, Zap70, and ERK (88). For a cell to tune its internal 
selection or activation thresholds, it must simultaneously modulate multiple signaling molecules with minimal sequence homology. In 2007, Li et al. (85) identified miR-181a as modulator of TCR sensitivity by controlling multiple intracellular signaling molecules. Only modest regulation of the phosphatases PTPN22, SHP-2, and DUSP6 by miR-181a was required to yield substantial differences in both activation and selection thresholds. Using retroviral overexpression, negative regulation of these phosphatases by miR-181a was confirmed via multiple methods including luciferase assay for target validation, and western blot and qPCR for visualization of reduced protein and mRNA levels, respectively, in the presence of increased miR-181a. An increase in both Lck and ERK phosphorylation could be seen in the presence of increased miR-181a (85), which is consistent with their reported dephosphorylation by PTPN22 and DUSP5/6, respectively $(89,90)$. Moreover, restoring DUSP6 expression to normal levels by co-expressing miR-181a and Dusp6 mRNA with mutated miR-181a target sites, reduces basal Lck serine phosphorylation to the background level (85). In addition to miR-181a overexpression studies, Li et al. also performed loss-of-function analyses using miR-181a antagomirs. Simulating thymocyte development in vitro using fetal thymic organ culture in the presence of miR-181a antagomirs and TCR antigens revealed a large reduction in negative selection and an impairment of positive selection, suggesting that miR-181a sets a threshold for selection in the thymus. Upon antagomir treatment in DP thymocytes, both mRNA and protein levels of PTPN22, SHP-2, DUSP5, and DUSP6 were elevated, along with a decrease in ERK activation. Therefore, miR-181a was identified as an intrinsic modulator of TCR sensitivity through targeting multiple negative regulators of TCR signaling providing an in vitro framework for the mechanism behind miR-181a's involvement in thymocyte selection. However, the role of miR181a in selection of conventional $\mathrm{T}$ cells in vivo appears to be complex and remains incompletely understood (86).

In contrast, miR-181 is critical for development of unconventional $\mathrm{T}$ cells, most notably iNKT and MAIT cells, but also Treg cells. Loss of miR-181a/b-1 resulted in a massive reduction in the iNKT cell compartment due to a block in the transition between S0 and S1, coupled with a reduced proliferation capacity (Figure 1). Consistent with the previously suggested function of miR-181 as modulator of TCR signaling, miR-181a/b-1-deficient thymocytes also displayed a decreased capacity to transmit signals through the TCR and iNKT-cell development was rescued in vivo through administration of supraphysiological levels of cognate $\alpha$-GalCer ligand (82). A $\mathrm{V} \alpha 14$-transgenic TCR was also shown to rescue the defect in iNKT-cell development in miR-181a/b-1-deficient mice (91). An independent study characterizing miR-181a/b-1-deficient mice suggested that the deficiency in iNKT-cell development was rather due direct targeting of Pten, suggesting that miR-181a/b-1 constitutes a metabolic rheostat during T-cell development (92). Although haploinsufficiency of Pten was able to partially rescue miR-181a/b-1-induced iNKT-cell development, another study showed that rescue by a V $\alpha 14 \mathrm{TCR} \alpha$ transgene did not alter PTEN levels (91). Although a dual function of miR-181a/b-1 for iNKT-cell development is conceivable, this finding suggested that targeting PTEN is most likely secondary over modulation of TCR signaling. Nevertheless, open questions concerning the discrepancies between phenotypes of the two independent mouse models persist.

Certain populations of $\gamma \delta$ T cells also depend on strong TCR signals for development. Surprisingly, $\gamma \delta \mathrm{T}$-cell development was largely independent of miR-181a/b-1 and found to be relatively normal in the absence of miR-181a/b-1 (82, 93). However, an increase in the liver $\gamma \delta$ NKT cell compartment was observed, attributable to homeostatic expansion in the absence of $\alpha \beta$ iNKT cells (93). The pool of $\gamma \delta$ NKT cells in the liver of miR-181a/b1 -deficient mice showed a reduced capacity to secrete IFN $\gamma$, perhaps hinting to a yet undefined role of miR-181 in IFN $\gamma$ regulation of $\mathrm{CD} 27^{+} \gamma \delta \mathrm{T}$ cells. Recent data show that both miR-181a and miR-181d are upregulated in $\mathrm{CD}_{2} 7^{+}$compared to $\mathrm{CD}^{-} 7^{-}$cells, which points toward a possible role in $\gamma \delta \mathrm{T}$ cell differentiation (93). In regard to this, it is important to note that normal miR-181d expression levels are present in miR181a/b-1-deficient mice and this could have an obscuring effect on miR-181a-deficiency.

MAIT cells can partially compensate for loss of iNKT cells, which is exemplified in the absence of CD1d. Alternatively, the many parallels in development of both unconventional $\mathrm{T}$ cell subsets might extend to a critical role for miR-181a/b-1 in MAIT-cell development as well, although it remains to be shown whether MAIT-cell selection also depends on strong TCR signals (41). Indeed, formation of MAIT cells was critically impaired in the absence of miR-181a/b-1 with a partial developmental block at S1 and severely limited proliferation of S2 cells (94) (Figure 2). As a consequence, residual MAIT cells in miR-181a/b-1-deficient mice failed to upregulate the key transcription factor PLZF. Notably, loss of miR-181a/b-1 results in a bona fide phenocopy of defective MAIT-cell development in pan-miRNA-deficient mice (20). Although loss of miR-181a/b-1 completely precluded intrathymic maturation of MAIT cells, some peripheral MAIT cells acquired PLZF and the MAIT1 transcription factor Tbet and to a much lesser extent the MAIT17 transcription factor ROR $\gamma$ t. These findings highlight the capacity of MAIT cells for extra-thymic terminal maturation. Bona fide MAITcell development was rescued by retrogenic expression of the invariant $\mathrm{V} \alpha 19$ TCR $\alpha$ chain, providing indirect evidence for agonist selection.

Use of a $\operatorname{Rag}^{\mathrm{GFP}}$ molecular timer to label freshly developing cells in the thymus, revealed a substantial defect in development of Treg cells in the absence of miR-181a/b-1 due to reduced TCR signaling (95) (Figure 3). Treg cells are generated from two different precursors. Foxp $3^{-} \mathrm{CD} 25^{+}$precursors receive strong TCR signals, whilst Foxp $3^{+} \mathrm{CD} 25^{-}$precursors are characterized by a history of somewhat weaker TCR signals $(5,36)$. The former are virtually unaffected by loss of miR-181a/b-1, suggesting that TCR signals in these precursors are either not sufficiently dampened or that this subset is replenished by thymocytes otherwise marked for clonal deletion. In contrast, formation of Foxp $3^{+} \mathrm{CD} 25^{-}$precursors is substantially delayed. Together, these data imply that either Foxp $3^{+} \mathrm{CD} 25^{-}$precursors constitute the major source of thymus-derived Treg cells or that loss of miR181a/b-1 imposes an additional block in Treg-cell development 


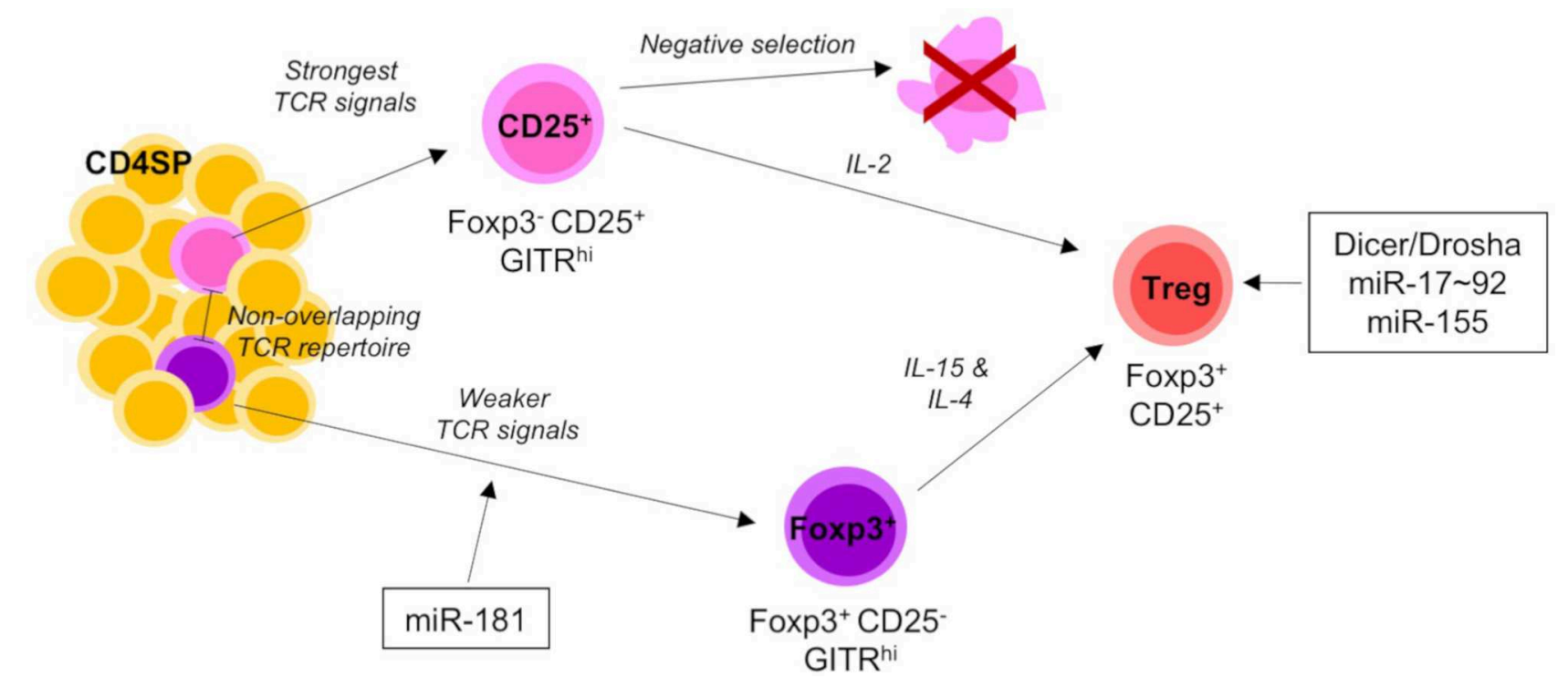

FIGURE 3 | miRNA-mediated control of Treg-cell development. Thymic-derived Treg-cell development begins at the CD4 SP stage of development and proceeds via one of two different pathways. The first Treg precursors to arise are the CD25+ population. CD25+ precursors require strong TCR signals and IL-2 signaling to mature into $\mathrm{CD}_{25}{ }^{+} \mathrm{Foxp}^{+}$Tregs. The alternative pathway of Treg-cell development is characterized by the generation of Foxp3 ${ }^{+}$precursors. Foxp3 ${ }^{+}$precursors develop from comparably weaker TCR signals to CD25+ precursors and share little TCR repertoire overlap. As they mature into Tregs they upregulate CD25 and require both IL-4 and IL-15 signaling. Mature Tregs emigrate from the thymus to join the peripheral T cell pool. Total (Dicer/Drosha) and individual miRNAs acting on distinct developmental transitions are indicated. Single positive (SP) and T cell receptor (TCR).

at the transition between Foxp $3^{-} \mathrm{CD} 25^{+}$precursors and mature Treg cells. Interestingly, loss of miR-181a/b-1 allowed for the generation of a numerically normal peripheral Treg-cell compartment through homeostatic expansion. In consequence, these Treg cells had a limited TCR diversity. Notably, peripheral murine Treg cells express very low levels of miR-181a/b1. Nevertheless, peripheral miR-181a/b-1-deficient Treg cells expressed elevated levels of CTLA-4 resulting in an increased suppressive capacity. The molecular mechanism resulting in elevated expression of CTLA-4 remains in part elusive.

In contrast to other miRNAs discussed so far, which display highly context-dependent functions in unconventional $\mathrm{T}$ cells, miR-181 as rheostat of TCR signaling has emerged as unifying master regulator of unconventional T cells. Of note, development of IELs remains ill-characterized with regard to regulation by miRNAs. However, the recent identification of more clearly defined intrathymic IEL precursors will be of substantial advantage for such an analysis (31).

\section{REGULATION OF MIRNA FUNCTION BEYOND DYNAMIC EXPRESSION}

T cells express over 600 different miRNAs, with individual miRNA expression levels differing as much as 1,000-fold throughout T-cell development. Dynamic mRNA composition as $T$ cells advance through development, alters the availability of miRNA recognition sites and therefore the miRNA "targetome" (84). Thus, many miRNAs may target one mRNA, while one
miRNA may target many mRNAs. Furthermore, recent reports suggest that miRNAs exhibit different targeting hierarchies in different cell types (96). Some striking examples of such dependency on cellular context have been highlighted above. However, recent evidence suggests that dynamic and/or high expression levels do not necessarily indicate functional relevance of a given miRNA.

miR-21 is prominently expressed in immature DN thymocytes followed by a massive decline toward more mature developmental stages $(84,97)$. Expression levels are high again in iNKT cells with miR-21 being the most highly upregulated when compared to conventional $\mathrm{T}$ cells, prompting it to be a potential candidate for iNKT-cell regulation (45). However, neither deletion nor its overexpression in mixed bone-marrow chimeric mice revealed a role of miR-21 for both conventional and unconventional T-cell development, including iNKT cells, Treg cells, and $\gamma \delta \mathrm{T}$ cells (97). The underlying mechanism for this apparent discrepancy between high levels of expression vs. lack of functional relevance remains elusive. A study comparing primary liver cells with cancer cells revealed that in primary cells miR-21 was largely unable to repress its predicted targets (98). This failure in repressive function was associated with limited recruitment to polysomes, whereas recruitment of miR-21 to polysomes was substantial in cancer cells, suggesting that the weak silencing capacity of miR-21 in primary cells is a consequence of selective redistribution of its target mRNAs away from polysomes.

Another recent study revealed that most cells contain reservoirs of low molecular weight RISCs (LMW-RISC) that 
are not associated with mRNAs and are therefore inactive (99). Upon T-cell activation, signal transduction pathways were demonstrated to increase the assembly of high molecular weight RISCs (HMW-RISC), which prompted miRNA-mediated repression, despite there being no net increase in miRNA expression (99). Interestingly, in both conditions miR-21 was preferentially detected in LMW-RISC, which is consistent with its limited repressive function. Another mechanism of post-transcriptional regulation of miRNA has recently been demonstrated to be $5^{\prime}$-end phosphorylation (100). This study showed that only 5 -end phosphorylated miR-34 was incorporated into RISCs and phosphorylation of mature, yet inactive miR-34, was dependent on DNA damage.

Overall, these studies highlight mechanisms of regulation of miRNA function beyond dynamic changes in expression. Understanding post-transcriptional modification of miRNAs is pivotal for a complete understanding of miRNA-

\section{REFERENCES}

1. Godfrey DI, Uldrich AP, McCluskey J, Rossjohn J, Moody DB. The burgeoning family of unconventional T cells. Nat Immunol. (2015) 16:111423. doi: $10.1038 /$ ni.3298

2. Legoux F, Salou M, Lantz O. Unconventional or preset $\alpha \beta \mathrm{T}$ cells: evolutionarily conserved tissue-resident $\mathrm{T}$ cells recognizing nonpeptidic ligands. Annu Rev Cell Dev Biol. (2017) 33:51135. doi: 10.1146/annurev-cellbio-100616-060725

3. McDonald BD, Jabri B, Bendelac A. Diverse developmental pathways of intestinal intraepithelial lymphocytes. Nat Rev Immunol. (2018) 18:51425. doi: 10.1038/s41577-018-0013-7

4. Crosby CM, Kronenberg M. Tissue-specific functions of invariant natural killer $\mathrm{T}$ cells. Nat Rev Immunol. (2018) 18:559-74. doi: 10.1038/s41577-018-0034-2

5. Moran AE, Holzapfel KL, Xing Y, Cunningham NR, Maltzman JS, Punt J, et al. $\mathrm{T}$ cell receptor signal strength in Treg and iNKT cell development demonstrated by a novel fluorescent reporter mouse. J Exp Med. (2011) 208:1279-89. doi: 10.1084/jem.201 10308

6. Feng Y, van der Veeken J, Shugay M, Putintseva EV, Osmanbeyoglu HU, Dikiy $\mathrm{S}$, et al. A mechanism for expansion of regulatory T-cell repertoire and its role in self-tolerance. Nature. (2015) 528:132-6. doi: 10.1038/nature 16141

7. Dashtsoodol N, Shigeura T, Aihara M, Ozawa R, Kojo S, Harada M, et al. Alternative pathway for the development of $\mathrm{V} \alpha 14+$ NKT cells directly from CD4-CD8- thymocytes that bypasses the CD4+CD8+ stage. Nat Immunol. (2017) 18:274-82. doi: 10.1038/ni.3668

8. Lambolez F, Arcangeli M-L, Joret A-M, Pasqualetto V, Cordier C, Di Santo JP, et al. The thymus exports long-lived fully committed $\mathrm{T}$ cell precursors that can colonize primary lymphoid organs. Nat Immunol. (2006) 7:7682. doi: $10.1038 /$ ni1293

9. Eberl G, Littman DR. The role of the nuclear hormone receptor RORgammat in the development of lymph nodes and Peyer's patches. Immunol Rev. (2003) 195:81-90. doi: 10.1034/j.1600-065X.2003.00074.x

10. Lantz O, Bendelac A. An invariant $T$ cell receptor alpha chain is used by a unique subset of major histocompatibility complex class I-specific CD4+ and CD4-8- T cells in mice and humans. J Exp Med. (1994) 180:1097106. doi: 10.1084/jem.180.3.1097

11. Wei DG, Curran SA, Savage PB, Teyton L, Bendelac A. Mechanisms imposing the $\mathrm{V} \beta$ bias of $\mathrm{V} \alpha 14$ natural killer $\mathrm{T}$ cells and consequences for microbial glycolipid recognition. J Exp Med. (2006) 203:1197-207. doi: 10.1084/jem.200 60418 mediated regulation in development and function of unconventional $\mathrm{T}$ cells.

\section{AUTHOR CONTRIBUTIONS}

SW and AK wrote the manuscript.

\section{FUNDING}

Research on miRNA and unconventional T cells in the lab of AK was funded by the German Research Foundation (DFG, grants: KR2320/5-1, SFB738-A7, SFB902-B15).

\section{ACKNOWLEDGMENTS}

We would like to sincerely thank Heike Kunze-Schumacher for providing assistance with manuscript preparation and revision.

12. Bendelac A, Lantz O, Quimby ME, Yewdell JW, Bennink JR, Brutkiewicz RR. CD1 recognition by mouse NK1+ T lymphocytes. Science. (1995) 268:863-5. doi: 10.1126/science.7538697

13. Benlagha $\mathrm{K}$, Kyin $\mathrm{T}$, Beavis $\mathrm{A}$, Teyton $\mathrm{L}$, Bendelac A. A thymic precursor to the NK $\mathrm{T}$ cell lineage. Science. (2002) 296:553-5. doi: 10.1126/science.1069017

14. Pellicci DG, Hammond KJ, Uldrich AP, Baxter AG, Smyth MJ, Godfrey DI. A natural killer T (NKT) cell developmental pathway ilnvolving a thymusdependent NK1.1(-)CD4(+) CD1d-dependent precursor stage. J Exp Med. (2002) 195:835-44. doi: 10.1084/jem.20011544

15. Berzins SP, McNab FW, Jones CM, Smyth MJ, Godfrey DI. Long-term retention of mature NK1.1+ NKT cells in the thymus. J Immunol. (2006) 176:4059-65. doi: 10.4049/jimmunol.176.7.4059

16. Lee YJ, Holzapfel KL, Zhu J, Jameson SC, Hogquist KA. Steady-state production of IL-4 modulates immunity in mouse strains and is determined by lineage diversity of iNKT cells. Nat Immunol. (2013) 14:114654. doi: 10.1038/ni.2731

17. Tilloy F, Treiner E, Park SH, Garcia C, Lemonnier F, de La Salle $H$, et al. An invariant $T$ cell receptor alpha chain defines a novel TAP-independent major histocompatibility complex class Ib-restricted alpha/beta $\mathrm{T}$ cell subpopulation in mammals. J Exp Med. (1999) 189:1907-21. doi: 10.1084/jem.189. 12.1907

18. Porcelli S, Yockey CE, Brenner MB, Balk SP. Analysis of T cell antigen receptor (TCR) expression by human peripheral blood CD4-8- alpha/beta $\mathrm{T}$ cells demonstrates preferential use of several $\mathrm{V}$ beta genes and an invariant TCR alpha chain. J Exp Med. (1993) 178:1-16. doi: 10.1084/jem.178.1.1

19. Treiner E, Duban L, Bahram S, Radosavljevic M, Wanner V, Tilloy F, et al. Selection of evolutionarily conserved mucosal-associated invariant T cells by MR1. Nature. (2003) 422:164-9. doi: 10.1038/nature01433

20. Koay H-F, Gherardin NA, Enders A, Loh L, Mackay LK, Almeida $\mathrm{CF}$, et al. A three-stage intrathymic development pathway for the mucosal-associated invariant T cell lineage. Nat Immunol. (2016) 17:130011. doi: $10.1038 /$ ni.3565

21. Salou M, Legoux F, Gilet J, Darbois A, Du Halgouet A, Alonso R, et al. A common transcriptomic program acquired in the thymus defines tissue residency of MAIT and NKT subsets. J Exp Med. (2019) 216:13351. doi: 10.1084 /jem.20181483

22. Kelly J, Minoda Y, Meredith T, Cameron G, Philipp M-S, Pellicci DG, et al. Chronically stimulated human MAIT cells are unexpectedly potent IL-13 producers. Immunol Cell Biol. (2019) 97:689-99. doi: 10.1111/imcb.12281

23. Savage AK, Constantinides MG, Han J, Picard D, Martin E, Li B, et al. The transcription factor PLZF directs the effector program of the NKT cell lineage. Immunity. (2008) 29:391-403. doi: 10.1016/j.immuni.2008.07.011 
24. Kovalovsky D, Uche OU, Eladad S, Hobbs RM, Yi W, Alonzo E, et al. The BTB-zinc finger transcriptional regulator PLZF controls the development of invariant natural killer T cell effector functions. Nat Immunol. (2008) 9:1055-64. doi: 10.1038/ni.1641

25. Lu Y, Zhong M-C, Qian J, Calderon V, Cruz Tleugabulova M, Mallevaey $\mathrm{T}$, et al. SLAM receptors foster iNKT cell development by reducing TCR signal strength after positive selection. Nat Immunol. (2019) 20:44757. doi: 10.1038/s41590-019-0334-0

26. Griewank K, Borowski C, Rietdijk S, Wang N, Julien A, Wei DG, et al. Homotypic interactions mediated by Slamf1 and Slamf6 receptors control NKT cell lineage development. Immunity. (2007) 27:751-62. doi: 10.1016/j.immuni.2007.08.020

27. Legoux F, Gilet J, Procopio E, Echasserieau K, Bernardeau K, Lantz O. Molecular mechanisms of lineage decisions in metabolite-specific T cells. Nat Immunol. (2019) 20:1244-55. doi: 10.1038/s41590-019-0465-3

28. Legoux F, Bellet D, Daviaud C, El Morr Y, Darbois A, Niort K, et al. Microbial metabolites control the thymic development of mucosal-associated invariant T cells. Science. (2019) eaaw2719. doi: 10.1126/science.aaw2719. [Epub ahead of print].

29. Ruscher R, Hogquist KA. Development, ontogeny, and maintenance of TCR $\alpha \beta+$ CD $8 \alpha \alpha$ IEL. Curr Opin Immunol. (2019) 58:838. doi: 10.1016/j.coi.2019.04.010

30. McDonald BD, Bunker JJ, Ishizuka IE, Jabri B, Bendelac A. Elevated $\mathrm{T}$ cell receptor signaling identifies a thymic precursor to the $\operatorname{TCR} \alpha \beta(+) \operatorname{CD} 4(-) \operatorname{CD} 8 \beta(-)$ intraepithelial lymphocyte lineage. Immunity. (2014) 41:219-29. doi: 10.1016/j.immuni.2014. 07.008

31. Ruscher R, Kummer RL, Lee YJ, Jameson SC, Hogquist KA. CD8 $\alpha \alpha$ intraepithelial lymphocytes arise from two main thymic precursors. Nat Immunol. (2017) 18:771-9. doi: 10.1038/ni.3751

32. Hsieh C-S, Zheng Y, Liang Y, Fontenot JD, Rudensky AY. An intersection between the self-reactive regulatory and nonregulatory $\mathrm{T}$ cell receptor repertoires. Nat Immunol. (2006) 7:401-10. doi: 10.1038/ni1318

33. Lio C-WJ, Hsieh C-S. A two-step process for thymic regulatory $\mathrm{T}$ cell development. Immunity. (2008) 28:10011. doi: 10.1016/j.immuni.2007.11.021

34. Burchill MA, Yang J, Vang KB, Moon JJ, Chu HH, Lio C-WJ, et al. Linked $\mathrm{T}$ cell receptor and cytokine signaling govern the development of the regulatory T cell repertoire. Immunity. (2008) 28:11221. doi: 10.1016/j.immuni.2007.11.022

35. Tai X, Erman B, Alag A, Mu J, Kimura M, Katz G, et al. Foxp3 transcription factor is proapoptotic and lethal to developing regulatory $\mathrm{T}$ cells unless counterbalanced by cytokine survival signals. Immunity. (2013) 38:1116-28. doi: 10.1016/j.immuni.2013. 02.022

36. Marshall D, Sinclair C, Tung S, Seddon B. Differential requirement for IL-2 and IL-15 during bifurcated development of thymic regulatory $\mathrm{T}$ cells. J Immunol. (2014) 193:5525-33. doi: 10.4049/jimmunol.14 02144

37. Owen DL, Mahmud SA, Sjaastad LE, Williams JB, Spanier JA, Simeonov $\mathrm{DR}$, et al. Thymic regulatory $\mathrm{T}$ cells arise via two distinct developmental programs. Nat Immunol. (2019) 20:195-205. doi: 10.1038/s41590-0180289-6

38. Garbe AI, Krueger A, Gounari F, Zúñiga-Pflücker JC, von Boehmer H. Differential synergy of Notch and $\mathrm{T}$ cell receptor signaling determines alphabeta versus gammadelta lineage fate. $J$ Exp Med. (2006) 203:1579-90. doi: 10.1084/jem.200 60474

39. van de Walle I, Waegemans E, de Medts J, de Smet G, de Smedt M, Snauwaert $\mathrm{S}$, et al. Specific Notch receptor-ligand interactions control human TCR$\alpha \beta / \gamma \delta$ development by inducing differential Notch signal strength. J Exp Med. (2013) 210:683-97. doi: 10.1084/jem.20121798

40. Verstichel G, Vermijlen D, Martens L, Goetgeluk G, Brouwer M, Thiault $\mathrm{N}$, et al. The checkpoint for agonist selection precedes conventional selection in human thymus. Sci Immunol. (2017) 2:eaah4232. doi: 10.1126/sciimmunol.aah4232

41. Koay H-F, Godfrey DI. MicroRNA-managing the development of MAIT cells. Immunol Cell Biol. (2019) 97:121-3. doi: 10.1111/imcb.12232
42. Guo H, Ingolia NT, Weissman JS, Bartel DP. Mammalian microRNAs predominantly act to decrease target mRNA levels. Nature. (2010) 466:83540. doi: 10.1038/nature09267

43. Friedman RC, Farh KK-H, Burge CB, Bartel DP. Most mammalian mRNAs are conserved targets of microRNAs. Genome Res. (2009) 19:92105. doi: 10.1101/gr.082701.108

44. Cobb BS, Nesterova TB, Thompson E, Hertweck A, O’Connor E, Godwin J, et al. T cell lineage choice and differentiation in the absence of the RNase III enzyme Dicer. J Exp Med. (2005) 201:1367-73. doi: 10.1084/jem.20050572

45. Fedeli M, Napolitano A, Wong MP, Marcais A, de Lalla C, Colucci F, et al. Dicer-dependent microRNA pathway controls invariant NKT cell development. J Immunol. (2009) 183:250612. doi: 10.4049/jimmunol.0901361

46. Zhou L, Seo K-H, He H-Z, Pacholczyk R, Meng D-M, Li C-G, et al. Tie2creinduced inactivation of the miRNA-processing enzyme Dicer disrupts invariant NKT cell development. Proc Natl Acad Sci USA. (2009) 106:1026671. doi: 10.1073/pnas.0811119106

47. Fedeli M, Riba M, Garcia Manteiga JM, Tian L, Viganò V, Rossetti G, et al. miR-17 92 family clusters control iNKT cell ontogenesis via modulation of TGF- $\beta$ signaling. Proc Natl Acad Sci USA. (2016) 113:E828695. doi: 10.1073/pnas.1612024114

48. Cobb BS, Hertweck A, Smith J, O'Connor E, Graf D, Cook T, et al. A role for Dicer in immune regulation. J Exp Med. (2006) 203:251927. doi: 10.1084/jem.20061692

49. Chong MMW, Rasmussen JP, Rudensky AY, Littman DR. The RNAseIII enzyme Drosha is critical in $\mathrm{T}$ cells for preventing lethal inflammatory disease. J Exp Med. (2008) 205:2005-17. doi: 10.1084/jem.200712190 $90508 \mathrm{c}$

50. Liston A, Lu L-F, O’Carroll D, Tarakhovsky A, Rudensky AY. Dicerdependent microRNA pathway safeguards regulatory $\mathrm{T}$ cell function. $J$ Exp Med. (2008) 205:1993-2004. doi: 10.1084/jem.20081062

51. Yuan J, Nguyen CK, Liu X, Kanellopoulou C, Muljo SA. Lin28b reprograms adult bone marrow hematopoietic progenitors to mediate fetal-like lymphopoiesis. Science. (2012) 335:1195-200. doi: 10.1126/science.1216557

52. Pobezinsky LA, Etzensperger R, Jeurling S, Alag A, Kadakia T, McCaughtry TM, et al. Let-7 microRNAs target the lineage-specific transcription factor PLZF to regulate terminal NKT cell differentiation and effector function. Nat Immunol. (2015) 16:517-24. doi: 10.1038/ni.3146

53. Doisne J-M, Becourt C, Amniai L, Duarte N, Le Luduec J-B, Eberl G, et al. Skin and peripheral lymph node invariant NKT cells are mainly retinoic acid receptor-related orphan receptor (gamma)t+ and respond preferentially under inflammatory conditions. J Immunol. (2009) 183:2142-9. doi: 10.4049/jimmunol.09 01059

54. Ouyang W, Beckett $\mathrm{O}, \mathrm{Ma}$ Q, Li MO. Transforming growth factor-beta signaling curbs thymic negative selection promoting regulatory $\mathrm{T}$ cell development. Immunity. (2010) 32:64253. doi: 10.1016/j.immuni.2010.04.012

55. Konkel JE, Maruyama T, Carpenter AC, Xiong Y, Zamarron BF, Hall BE, et al. Control of the development of CD8 $\alpha \alpha+$ intestinal intraepithelial lymphocytes by TGF- $\beta$. Nat Immunol. (2011) 12:312-9. doi: 10.1038/ni.1997

56. Chen W, Frank ME, Jin W, Wahl SM. TGF-beta released by apoptotic $\mathrm{T}$ cells contributes to an immunosuppressive milieu. Immunity. (2001) 14:715-25. doi: 10.1016/S1074-7613(01)00147-9

57. Regelin M, Blume J, Pommerencke J, Vakilzadeh R, Witzlau K, Łyszkiewicz $\mathrm{M}$, et al. Responsiveness of developing $\mathrm{T}$ cells to IL-7 signals is sustained by miR-17 92. J Immunol. (2015) 195:4832-40. doi: 10.4049/jimmunol.14 02248

58. Ventura A, Young AG, Winslow MM, Lintault L, Meissner A, Erkeland SJ, et al. Targeted deletion reveals essential and overlapping functions of the miR-17 through 92 family of miRNA clusters. Cell. (2008) 132:87586. doi: 10.1016/j.cell.2008.02.019

59. Han Y-C, Vidigal JA, Mu P, Yao E, Singh I, González AJ, et al. An allelic series of miR-17 92-mutant mice uncovers functional specialization and cooperation among members of a microRNA polycistron. Nat Genet. (2015) 47:766-75. doi: 10.1038/ng.3321

60. Coombes JL, Siddiqui KR, Arancibia-Cárcamo CV, Hall J, Sun C-M, Belkaid $\mathrm{Y}$, et al. A functionally specialized population of mucosal CD103+ DCs 
induces Foxp3+ regulatory $\mathrm{T}$ cells via a TGF-beta and retinoic aciddependent mechanism. J Exp Med. (2007) 204:1757-64. doi: 10.1084/jem.200 70590

61. Li MO, Sanjabi S, Flavell RA. Transforming growth factor-beta controls development, homeostasis, and tolerance of $\mathrm{T}$ cells by regulatory $\mathrm{T}$ cell-dependent and -independent mechanisms. Immunity. (2006) 25:455-71. doi: 10.1016/j.immuni.2006. 07.011

62. Liu Y, Zhang P, Li J, Kulkarni AB, Perruche S, Chen W. A critical function for TGF-beta signaling in the development of natural CD4+CD25+Foxp3+ regulatory T cells. Nat Immunol. (2008) 9:632-40. doi: 10.1038/ni.1607

63. Marie JC, Letterio JJ, Gavin M, Rudensky AY. TGF-betal maintains suppressor function and Foxp3 expression in CD4+CD25+ regulatory $\mathrm{T}$ cells. J Exp Med. (2005) 201:1061-7. doi: 10.1084/jem.200 42276

64. Marie JC, Liggitt D, Rudensky AY. Cellular mechanisms of fatal early-onset autoimmunity in mice with the $\mathrm{T}$ cell-specific targeting of transforming growth factor-beta receptor. Immunity. (2006) 25:44154. doi: 10.1016/j.immuni.2006.07.012

65. de Kouchkovsky D, Esensten JH, Rosenthal WL, Morar MM, Bluestone JA, Jeker LT. microRNA-17-92 regulates IL-10 production by regulatory $\mathrm{T}$ cells and control of experimental autoimmune encephalomyelitis. J Immunol. (2013) 191:1594-605. doi: 10.4049/jimmunol.12 03567

66. Yang H-Y, Barbi J, Wu C-Y, Zheng Y, Vignali PD, Wu X, et al. MicroRNA-17 modulates regulatory $\mathrm{T}$ cell function by targeting coregulators of the Foxp3 transcription factor. Immunity. (2016) 45:8393. doi: 10.1016/j.immuni.2016.06.022

67. Bezman NA, Chakraborty $T$, Bender T, Lanier LL. miR150 regulates the development of NK and iNKT cells. J Exp Med. (2011) 208:2717-31. doi: 10.1084/jem.201 11386

68. Zheng Q, Zhou L, Mi Q-S. MicroRNA miR-150 is involved in Va14 invariant NKT cell development and function. J Immunol. (2012) 188:211826. doi: 10.4049/jimmunol.1103342

69. Benlagha K, Wei DG, Veiga J, Teyton L, Bendelac A. Characterization of the early stages of thymic NKT cell development. J Exp Med. (2005) 202:485-92. doi: 10.1084/jem.20050456

70. Xiao C, Calado DP, Galler G, Thai T-H, Patterson HC, Wang J, et al. MiR-150 controls B cell differentiation by targeting the transcription factor $\mathrm{c}-\mathrm{Myb}$. Cell. (2007) 131:146-59. doi: 10.1016/j.cell.2007.07.021

71. Seo S-H, Jang MS, Kim D-J, Kim S-M, Oh S-C, Jung C-R, et al. MicroRNA-150 controls differentiation of intraepithelial lymphocytes through TGF- $\beta$ receptor II regulation. I Allergy Clin Immunol. (2018) 141:1382-94.e14. doi: 10.1016/j.jaci.2017. 07.019

72. Frias AB, Buechel HM, Neupane A, D'Cruz LM. Invariant natural killer T-cell development and function with loss of microRNA-155. Immunology. (2018) 153:238-45. doi: 10.1111/imm.12836

73. Burocchi A, Pittoni P, Tili E, Rigoni A, Costinean S, Croce CM, et al. Regulated expression of miR-155 is required for iNKT cell development. Front Immunol. (2015) 6:140. doi: 10.3389/fimmu.2015.00140

74. Choi H-J, Geng Y, Cho H, Li S, Giri PK, Felio K, et al. Differential requirements for the Ets transcription factor Elf-1 in the development of NKT cells and NK cells. Blood. (2011) 117:1880-7. doi: 10.1182/blood-2010-09-3 09468

75. Walunas TL, Wang B, Wang CR, Leiden JM. Cutting edge: the Ets1 transcription factor is required for the development of NK T cells in mice. J Immunol. (2000) 164:2857-60. doi: 10.4049/jimmunol.164.6.2857

76. Felices M, Berg LJ. The Tec kinases Itk and Rlk regulate NKT cell maturation, cytokine production, and survival. J Immunol. (2008) 180:300718. doi: 10.4049/jimmunol.180.5.3007

77. Marson A, Kretschmer K, Frampton GM, Jacobsen ES, Polansky JK, MacIsaac KD, et al. Foxp3 occupancy and regulation of key target genes during T-cell stimulation. Nature. (2007) 445:931-5. doi: 10.1038/nature 05478
78. Lu L-F, Thai T-H, Calado DP, Chaudhry A, Kubo M, Tanaka K, et al. Foxp3-dependent microRNA155 confers competitive fitness to regulatory T cells by targeting SOCS1 protein. Immunity. (2009) 30:8091. doi: 10.1016/j.immuni.2008.11.010

79. Kohlhaas S, Garden OA, Scudamore C, Turner M, Okkenhaug K, Vigorito E. Cutting edge: the Foxp3 target miR-155 contributes to the development of regulatory T cells. J Immunol. (2009) 182:257882. doi: 10.4049/jimmunol.0803162

80. Yao R, Ma Y-L, Liang W, Li H-H, Ma Z-J, Yu X, et al. MicroRNA-155 modulates Treg and Th17 cells differentiation and Th17 cell function by targeting SOCS1. PLoS ONE. (2012) 7:e46082. doi: 10.1371/journal.pone.00 46082

81. Lu L-F, Gasteiger G, Yu I-S, Chaudhry A, Hsin J-P, Lu Y, et al. A Single miRNA-mRNA interaction affects the immune response in a context- and cell-type-specific manner. Immunity. (2015) 43:5264. doi: 10.1016/j.immuni.2015.04.022

82. Zietara N, Łyszkiewicz M, Witzlau K, Naumann R, Hurwitz $\mathrm{R}$, Langemeier J, et al. Critical role for miR-181a/b-1 in agonist selection of invariant natural killer $\mathrm{T}$ cells. Proc Natl Acad Sci USA. (2013) 110:7407-12. doi: 10.1073/pnas.12219 84110

83. Neilson JR, Zheng GX, Burge CB, Sharp PA. Dynamic regulation of miRNA expression in ordered stages of cellular development. Genes Dev. (2007) 21:578-89. doi: 10.1101/gad.1522907

84. Kirigin FF, Lindstedt K, Sellars M, Ciofani M, Low SL, Jones L, et al. Dynamic microRNA gene transcription and processing during T cell development. $J$ Immunol. (2012) 188:3257-67. doi: 10.4049/jimmunol.1103175

85. Li Q-J, Chau J, Ebert PJ, Sylvester G, Min H, Liu G, et al. miR-181a is an intrinsic modulator of $\mathrm{T}$ cell sensitivity and selection. Cell. (2007) 129:147-61. doi: 10.1016/j.cell.2007.03.008

86. Schaffert SA, Loh C, Wang S, Arnold CP, Axtell RC, Newell $\mathrm{EW}$, et al. mir-181a-1/b-1 modulates tolerance through opposing activities in selection and peripheral $\mathrm{T}$ cell function. J Immunol. (2015) 195:1470-9. doi: 10.4049/jimmunol.14 01587

87. Ebert PJ, Jiang S, Xie J, Li Q-J, Davis MM. An endogenous positively selecting peptide enhances mature $\mathrm{T}$ cell responses and becomes an autoantigen in the absence of microRNA miR-181a. Nat Immunol. (2009) 10:11629. doi: 10.1038/ni.1797

88. Mustelin T, Vang T, Bottini N. Protein tyrosine phosphatases and the immune response. Nat Rev Immunol. (2005) 5:43-57. doi: 10.1038/nri1530

89. Wu J, Katrekar A, Honigberg LA, Smith AM, Conn MT, Tang J, et al. Identification of substrates of human protein-tyrosine phosphatase PTPN22. J Biol Chem. (2006) 281:11002-10. doi: 10.1074/jbc.M6004 98200

90. Theodosiou A, Ashworth A. MAP kinase phosphatases. Genome Biol. (2002) 3:reviews3009.1-reviews3009.10. doi: 10.1186/gb-2002-3-7-reviews3009

91. Blume J, zur Lage S, Witzlau K, Georgiev H, Weiss S, Łyszkiewicz M, et al. Overexpression of Va14Ja18 TCR promotes development of iNKT cells in the absence of miR-181a/b-1. Immunol Cell Biol. (2016) 94:7416. doi: $10.1038 /$ icb. 2016.40

92. Henao-Mejia J, Williams A, Goff LA, Staron M, Licona-Limón P, Kaech SM, et al. The microRNA miR-181 is a critical cellular metabolic rheostat essential for NKT cell ontogenesis and lymphocyte development and homeostasis. Immunity. (2013) 38:984-97. doi: 10.1016/j.immuni.2013.02.021

93. Sandrock I, Zietara N, Łyszkiewicz M, Oberdörfer L, Witzlau K, Krueger A, et al. MicroRNA-181a/b-1 is not required for innate $\gamma \delta$ NKT effector cell development. PLoS ONE. (2015) 10:e0145010. doi: 10.1371/journal.pone.01 45010

94. Winter SJ, Kunze-Schumacher H, Imelmann E, Grewers Z, Osthues T, Krueger A. MicroRNA miR-181a/b-1 controls MAIT cell development. Immunol Cell Biol. (2019) 97:190-202. doi: 10.1111/imcb.12211

95. Łyszkiewicz M, Winter SJ, Witzlau K, Föhse L, Brownlie R, Puchałka J, et al. miR-181a/b-1 controls thymic selection of Treg cells and tunes their suppressive capacity. PLoS Biol. (2019) 17:e2006716. doi: $10.1371 /$ journal.pbio.20 06716 
96. Hsin J-P, Lu Y, Loeb GB, Leslie CS, Rudensky AY. The effect of cellular context on miR-155-mediated gene regulation in four major immune cell types. Nat Immunol. (2018) 19:1137-45. doi: 10.1038/s41590-018-0208-x

97. Kunze-Schumacher H, Winter SJ, Imelmann E, Krueger A. miRNA miR-21 is largely dispensable for intrathymic T-cell development. Front Immunol. (2018) 9:2497. doi: 10.3389/fimmu.2018. 02497

98. Androsavich JR, Chau BN, Bhat B, Linsley PS, Walter NG. Disease-linked microRNA-21 exhibits drastically reduced mRNA binding and silencing activity in healthy mouse liver. RNA. (2012) 18:1510-26. doi: 10.1261/rna.033308.112

99. La Rocca G, Olejniczak SH, González AJ, Briskin D, Vidigal JA, Spraggon $\mathrm{L}$, et al. In vivo, Argonaute-bound microRNAs exist predominantly in a reservoir of low molecular weight complexes not associated with mRNA. Proc Natl Acad Sci USA. (2015) 112:767-72. doi: 10.1073/pnas.1424217112
100. Salzman DW, Nakamura K, Nallur S, Dookwah MT, Metheetrairut C, Slack FJ, et al. miR-34 activity is modulated through 5'-end phosphorylation in response to DNA damage. Nat Commun. (2016) 7:10954. doi: 10.1038/ncomms10954

Conflict of Interest: The authors declare that the research was conducted in the absence of any commercial or financial relationships that could be construed as a potential conflict of interest.

Copyright $\odot 2019$ Winter and Krueger. This is an open-access article distributed under the terms of the Creative Commons Attribution License (CC BY). The use, distribution or reproduction in other forums is permitted, provided the original author(s) and the copyright owner(s) are credited and that the original publication in this journal is cited, in accordance with accepted academic practice. No use, distribution or reproduction is permitted which does not comply with these terms. 